\title{
Entrepreneurs' Response to the Dark Side of Knowledge During Covid19
}

\author{
Brock Smith \\ University of Victoria \\ $\underline{\text { Smithb@uvic.ca }}$
}

\author{
Claudia Smith \\ University of Victoria \\ cgsmith@uvic.ca
}

\begin{abstract}
Small business entrepreneurs faced tremendous knowledge-based challenges during COVID19. Some entrepreneurs, even in the same industry sector and city, with similar offerings, responded to these knowledge challenges in diverse ways. For instance, some chose to adopt online store technologies while others did not. In this study, we investigate differences in retail small business entrepreneurs' COVID19 resilience enactment using a qualitative retroductive-analytic approach. Identity motives were uncovered as a likely explanatory construct, as those with externally-focused identity motives generally adopted these technologies while those with internally-focused identity motives generally did not. In addition, identity motives appear to influence entrepreneurs' perceptions of technology affordances, potentially moderating the impact of these perceptions on technology adoption decisions. Contrary to conceptualizations of individual resilience being a trait, we find support that resilience is a mindset. Implications for entrepreneurship theory, practice, and education are discussed.
\end{abstract}

\section{Introduction}

Small business and entrepreneurship researchers have always relied on efficient flows of believable knowledge from trustworthy knowledge stocks to develop and execute novel business models. Such knowledge transfers have allowed them to remain resilient even in times of severe exogenous shocks [e.g., $1,2]$. The Covid19 pandemic, however, was unique in magnitude, destructiveness, immediacy, duration, global impact, and uncertainty, and was consistent with what Winn, Kirchgeorg [3] call a Massive Discontinuous Change (MDC) event. Importantly from a knowledge perspective, COVID19 was plagued with not only constantly changing information, but also misinformation, and disinformation, creating significant knowledge uncertainty. The bright side of knowledge that entrepreneurs had relied on for market information etc. turned dark. Not only did the volume, veracity and variety of knowledge flows change (meaning more and more information came at entrepreneurs, faster and faster, in a number of formats), but more importantly, the veracity of such knowledge flows was now highly questionable, leading to an overall doubt in the value of information at the disposal of entrepreneurs. Against this backdrop, the COVID19 pandemic provides a compelling context for the study of small business entrepreneurs' resilience for two reasons. First, extreme events are useful for assessing boundary conditions of theory and concepts. Second, the pandemic's broad, deep, and quick impact reduced the masking effects of differential contexts. MDC events are expected to increase in frequency [3], making their study particularly important to entrepreneurs.

The COVID19 pandemic threatened many small businesses, everywhere, and all within a few days. Some businesses were mandated to close, while many others faced the choice of whether or not (and how) to continue operations; all relying on the same imperfect and frequently changing information. Consequently, this event offers a unique opportunity to observe what might otherwise be extremely difficult to "catch in action" - how entrepreneurs make strategic decisions when faced by unexpected external threats to the survivability of their small businesses. Understanding how strategic decisions were formulated by entrepreneurs, at the point when the serious impact of COVID19 first became clear, provides insights into resilience as a dynamic process of adjustment [e.g., 4].

Prior research on disasters, shocks, jolts, and crises [e.g., 5, 6] mainly examines macro-level negative impacts, such as reduced employment [7], and macrolevel positive impacts of crises, such as persistence and opportunity realization [8]. It also examines micro-level positive impacts such as self-sufficiency [9], and identity clarification [10]. We found no prior research on how positive and negative micro-foundational factors, including response to knowledge stocks, impact entrepreneurs' decision-making in times of crisis to enact resilience. Yet such decisions often determine the fate of small businesses, which are typically less able to survive poor decisions during crisis [11]. 
In the present study, we begin to address this gap by investigating the research question: Why did retail small business entrepreneurs enact resilience differently in responses to COVID19? Adopting a qualitative, retroductive analytic approach, we interviewed 15 entrepreneurs in five retail sectors, including clothing, shoes, pet supplies, toys, and curios (candles, cards, gifts, etc.), to investigate differential resilience enactment during the first wave of COVID19 (between mid-March and June of 2020). We chose to focus on small business retail entrepreneurs because in our community they were never mandated to close. Some of these entrepreneurs chose to close their stores, when others did not, reflecting real choice. In so doing, we answer the call by Dodd, Anderson [12] for more research investigating "everyday entrepreneurs."

Inductive analysis of our initial interviews led us to pinpoint a distinct resilience decision response some small retail entrepreneurs adopted online store technologies in response to COVID19, while others did not. Through a retroductive analytic process, we revealed a number of hidden insights on the mechanisms at play in the resilience response choices of entrepreneurs to adopt an online store.

\section{Methods}

Positioned in the critical realism paradigm, in which methodological considerations center on the retroductive nature of explanatory inquiry [13] our work examines the individual entrepreneur (level of analysis) and venture-related decision-making (unit of analysis). As deemed appropriate for critical realismbased qualitative research [14] we undertook theoretical and literal replication logic rather than sampling logic. We purposively selected respondents that the researchers believed could shed significant light on our research question [15]. In doing so, we reached out to small business owners, in our mid-sized Canadian community, who operated retail consumer goods stores, with fewer than 30 employees. We conducted and recorded Zoom-based interviews of 60 to 90 minutes with entrepreneurs who operated toy stores, pet stores, clothing stores and shoe stores. We began by seeking to answer the general question, "Why did retail small business entrepreneurs enact different resilience responses to COVID19?",

Consistent with the critical realism paradigm, a qualitative analytic approach for theory-building, and recommendations from Danermark, Ekström [16], we undertook an iterative series of research activities that included: description; analytical resolution; abduction and theoretical redescription; retroduction; comparison of theories and abstraction from data; and concret- ization and contextualization. These are described below.

With respect to description, we created, for each respondent, a comprehensive description of their COVID19 action responses to gain a clear understanding of timelines and strategic decisions. We noted markedly different descriptions provided by our first four respondents (owner-operators of a shoe store, clothing store, pet store, and toy store), despite their shared MDC context. Adopting a convergent interview approach consistent with critical realism [17], this led us to selectively seek more of these types of retailers to assess whether or not observed differences were simply related to the specific nature of their businesses and product lines.

We observed that some retailers who competed in the same space closed, even when not mandated, while others stayed fully open. Some closed temporarily (less than two weeks), and some for an extended period of time (four to 12 weeks). Some transitioned entirely to online sales, or adopted a hybrid approach of limited instore (or curbside pickup) and online sales. Some increased their use of social media to connect with customers, and others did not change their use of digital technology at all. These observed responses are found in the typology of crisis responses developed by Davidsson and Gordon [8].

Our analysis of this early data led us to examine differences in the decisions of retail small business entrepreneurs to adopt (or significantly expand) an online store as a resilience enacting strategic response, despite having rejected this decision prior to the COVID19 crisis. We were intrigued because a number of store owners said that they adopted an online store despite believing that it might be a money-losing decision. We wondered what was hidden from view that might explain this seemingly irrational decision. This led us to modify our initial research question to "Why did retail small business entrepreneurs choose different online store technology adoption strategies in response to COVID19." At this point, we selectively interviewed owners to capture variation in knowledge stocks and in whether or not they created an online store in response to the pandemic, or significantly expanded one that was little used.

With respect to analytical resolution, we continued to analyze our data and interview new respondents until we reached theoretical saturation and diminishing returns which [18] suggests can be between 10-15 interviews, and for us was reached at 15 interviews. Reflecting that a disproportionate percentage of retail small business entrepreneurs in our region are women, we spoke to mostly female owneroperators. Using NVivo tools, we first undertook an inductive process that moved from examining 
respondents' actions to examining their retrospective recollections related to these action decisions. We created first order and second order codes to help us to better understand emerging themes and our phenomenon of interest. As is important in qualitative inquiry, we also triangulated our interview data with information from company and competitive websites, and stories about some of our respondents found in local media coverage of the pandemic.

Consistent with the critical realism paradigm, and with respect to abduction and theoretical redescription, retroduction, and comparison of theories and abstraction from the data, we also continued "reading... [the literature]... while interviews are proceeding, enfolding the literature around the findings as they emerge from the interviews [14, p. 1202]. Iteratively analyzing our preliminary and aggregate codes, while revisiting the literature, we sought patterns in our data that provided insights to the decisionmaking processes of our respondents. Through an abduction process that included the generation and consideration of alternative theoretical explanations, we uncovered identity process theory as offering new insights into our data. Following the iterative nature of retrospection [14], at this stage we sought additional respondents who could offer us a new perspective such as an owner who felt her operation was not threatened by COVID19, and one who stayed closed for a very long time. This helped to ensure that we were fully exploring our phenomenon of interest [19]. Consistent with our critical realism research approach, at this point we saw patterns emerge in the application of identity motives, leading us to generate aggregate codes and themes from theory, rather than from the data [14].

With respect to concretization and contextualization, as the influence of threats to identity motives came into view as an important mechanism in the resilience decision processes of our respondents, we were able to revisit other dynamics that arose from our inductive interview analysis. These insights helped to build out a more comprehensive understanding of our research question that included technology affordances, digital literacy, and resilience mindset.

\section{Findings}

Among our respondents, we observed four different resilience enactment responses to the COVID19 pandemic. First, some retail entrepreneurs focused on dark-side information and closed for an extended period of time (4 to 12 weeks). Although slow to re-open face-to-face, many increased their social media presence to maintain relationships with customers, drive phone or email orders, let customers know they were open for curbside pick-up, or to let customers know when they would be fully open again. Second, some closed for a couple of weeks, but focused on bright-side knowledge to remain optimistic and then adapted more quickly and re-opened by conforming to health regulations and guidelines. Third, other brightside knowledge focused entrepreneurs developed online stores, or significantly enhanced their use of an existing one, and did so quickly, within two or three weeks. Finally, still others took much longer sort through knowledge stocks, eventually develop an online store, but took four or more weeks to do this. These responses are captured in Table 1. We noted different online store technology adoption decisions within retail sectors, within the same neighborhoods, and between businesses of similar size and products. Consequently, COVID19 resilience enactment did not appear to be explained by sector, size, product line, customers, organization, or geography context factors.

[Insert Table 1 Retail Entrepreneurs' Strategic Response to the First Wave of COVID19 About Here]

\subsection{Affordance Perceptions}

Unlike Priyono et al. [20], we did not find evidence that digital transformation of SMEs during the COVID19 pandemic was related to digital maturity. We did find evidence, however, that all of the retail entrepreneurs we interviewed who had not previously developed an online store, were very cognizant of the disabling affordances of online store technology. They identified numerous concerns and challenges for why they did not develop an online store during the first stage of the COVID19 pandemic, or why they had not done so before. These included practical concerns about the time, effort and cost of developing an online store, concerns about the perceived difficulty of developing an online store, strategic effectiveness concerns related to value proposition consistency, competitive visibility, and the difficulty of doing an online store well, and implementation concerns about system compatibility and security. This suggests a robust knowledge stock assessment relative to the pro's and con's of strategic response to the crisis. These findings are consistent with affordance theory (Volkoff \& Strong, 2018) and are not interesting in themselves.

More compelling is our finding that, in the crisis context of assessing available knowledge, those who did decide to develop an online store found enabling affordances that won over these concerns, and it was typically only one or two enabling affordances that tipped the scale. This despite these entrepreneurs 
recognizing that the financial benefits of doing so might not justify the time, effort, and expense.

Both those who increased their social media presence, and those who developed or enhanced online sales capability, did so to maintain customer relationships. But those who developed or enhanced online sales capability also expressed that this technology enabled them to engage with customers by servicing their needs, adding value, and creating better qualified in-store customers. Online stores were also seen as offering legitimacy to their operation through presence and credibility, and in one case (R3) to provide differentiation. Two respondents (R4 and R2) identified that the technology enabled them to experiment or take an incremental approach to dealing with COVID19 since service contracts and fees were monthly. Yet these same enabling affordances were available to the entrepreneurs who chose not to develop an online store; for some reason these entrepreneurs viewed or interpreted these affordances differently, and we were curious as to why.

When probed for why they did, or did not, create an online store in response to the first wave of the COVID19 pandemic, our entrepreneurs expressed a number of motivations. Many expressed financial motivations for either staying open, or developing an online store. R1 said: "At some point we just felt embarrassed. People were thanking us for being open as if it was some selfless act... We were just grateful to be open, to be allowed to be open, because we don't want our business to fail." R13 said: "Unfortunately I had received the majority of my summer stock just before we closed. So I had \$60,000 in bills that I had to pay... That's what made me decide to start with the private appointments."

Others expressed concerns about their own safety. $\mathrm{R} 1$, for example, also described "We just started to refocus on how we were going to operate safely for ourselves, safeguard our own wellbeing while still remaining open." R2 identified peer-pressure as a motivation for opening her store after being closed for three months, saying: "I opened up again because of peer-pressure from the rest of the town [other retailers and customers]. I definitely did not feel ready. People were asking me every day when I was opening. The stress of answering them became just as bad as the stress of just opening." But we found that most of our respondents expressed concerns about losing who they were, not being able to do what they loved, losing relationships with employees or customers, or loosing their sense of purpose. These sentiments seemed, through abductive and retroductive analysis, to point to their personal identity. Following Suddaby [21] we went back to the literature to better understand the impact of identity on entrepreneurial decisions.

\subsection{Identity motives}

Identity process theory identifies six broadly accepted personal identity-based motives (hereafter, identity motives) for behavior [22]. Self-esteem motive reflects people seeing themselves in a positive light or feeling better about themselves. Continuity motive reflects people protecting their identity over time; stable and linked to past, present and future identity. Distinctiveness motive reflects people differentiating themselves from others. Meaning motive reflects people seeing their lives as meaningful. Efficacy motive reflects people feeling competent and capable of influencing their environment. And finally, belonging motive reflects people feeling included and accepted by others. Multiple identity motives can be held at the same time, and generally, they are satisfied without the need for conscious reflection by the individual, exerting influence at a level of abstraction beyond where most people focus their attention, and hence need to be inferred [23]. While people are motivated by identity, they are also motivated by threats to their personal identity that undermine or degrade their beliefs, values, abilities, personality or other personal characteristics [24]. Times of crisis, like an MDC event, with high degrees of information uncertainty, heighten perceived threats to these identity motives [22] and COVID19 may have threatened the personal identities of entrepreneurs because it threatened their livelihood, confidence, status, and overall self as an entrepreneur. Threats to identity motives trigger re-evaluation of these motives, and hence behavior [25].

When we overlaid identity process theory on our first-order coding of the retail entrepreneurs' motives for their COVID19 resilience enactment responses, we saw alignment with all six of the identity motives specified by identity process theory. This suggests that identity motives, and in particular, knowledge-based threats to those motives, may play an important role in retail entrepreneurs' resilience enactment. Our first order codes, derived from inductive analysis, help to enhance identity process theory by uncovering observed dimensions of identity motives among retail entrepreneurs. This analysis, available from the authors, provides a more nuanced understanding of identity motives than in previous literature, and suggests the need for further examination of dimensions or expressions of these threats in additional contexts.

Additionally, we found evidence suggesting threats to identity motives may help explain why entrepreneurs viewed or interpreted the affordances of online sales platforms differently. While the COVID19 pandemic raised the salience of threat to continuity identity motives for many of our interviewed entrepreneurs, the entrepreneurs who developed (or significantly 
enhanced) an online store more frequently expressed sentiments relating to meaning and belonging identity motives, than those who did not develop an online store. In this regard, the identity motives of those who developed (or significantly enhanced) an online store were more externally focused (self in relation to others), than the identity motives of those who did not develop an online store (Table 1). This is interesting because it suggests that threats to identity motives may influence how entrepreneurs interpret technology affordances. Those with greater emphasis on externally-focused identity motives such as meaning and belonging, were also the entrepreneurs who viewed the enabling affordances of online store platform technologies more positively. This may suggest that small retail entrepreneurs who adopted online sales technologies viewed enabling affordances as helping them address threats to their identity motives. Those who did not develop an online store did not view the enabling affordances of online store technology as being a solution to ameliorating threats to their identity motives. This assessment, of course, is not conscious.

This possible relationship is illuminated in respondent vignettes available from the authors. Our findings suggest that identity motives may have direct impact on technology adoption resilience enactment and moderate the relationship between perception of technology affordances and technology adoption resilience enactment. Future research is needed to verify these relationships, but our findings suggest that identity motives may influence how entrepreneurs interpret knowledge.

\subsection{Resilience mindset}

A third theme evident in our interviews with small retail entrepreneurs relates to resilience mindset. For the most part, the entrepreneurs who developed or significantly enhanced online sales capability had a "surgite" (push on, or onwards) mentality when faced with the first wave of the COVID19 pandemic. Those who overcame the dark side of knowledge uncertainty expressed sentiments relating to resilience, such as being ready for change or having a "get it done" mentality, and responded more quickly to the COVID19 crisis. They expressed sentiments such as those shared by respondent R9: "When your back is up against a wall, you just do it, you get it done;" or R5 "you just can't be afraid to reinvent yourself" when describing what they were thinking and feeling when they first realized that COVID19 was serious. This suggests that resilience, rather than being a trait, characteristic, or attribute, may be better conceptualized for entrepreneurs as a mindset, a way of thinking about adversity. R2, for example said: "I'm a push forward with no concept of what my plan is person. I would rather die than sit back and do nothing... I don't know how you could be an entrepreneur without that mindset."

In contrast, the entrepreneurs who did not develop an online store, or significantly enhance an existing one, expressed sentiments about enjoying the time off, being reluctant to re-open, not being able to make plans, and needing to go with the flow. These sentiments suggested being fatalistic, that they were accepting that they really could not do much about the situation or their response, or that they were not able to prevent it or control it.

The entrepreneurs who adopted online store technology exhibited differential identity motives and a resilience mindset. While qualitative research precludes causal inferences, theory would suggest that the reason entrepreneurs acted was due to their resilience mindset, but how they chose to act was driven by their motivations. This is because resilience enactment can take many forms [8], while identity-based motivation is linked to specific action [26].

\section{Discussion}

Our findings revealed that the resilience enactment decisions of entrepreneurs, faced with questionable and constantly changing information, are central to their survival and performance [27]. This is particularly true for small business owners who typically do not have the financial, human, or social capital to recover from poor decisions [11], especially when faced with unexpected external change events such as the COVID19 pandemic. The unique situation of the COVID19 MDC event where almost all entrepreneurs were forced to make a strategic decision very quickly, with high and very similar levels of uncertainty, enabled investigation of resilience enactment decision processes previously obscured by differences in context. Through matching case studies, within and across retail sectors to further reduce the impact of context, we revealed a previously unknown insight that entrepreneurs make technology-adoption resilience enactment decisions consistent with threats to their identity motives. This has implications for theory, practice, and education.

\subsection{Contributions to theory}

First, there is growing interest in digitalization that examines entrepreneurs' adoption of technology. Technology is often central to enacted strategy and a key source of competitive advantage, but how entrepreneurs actually make technology adoption decisions is poorly understood. This discussion is only 
beginning to consider the role of technology affordances as an important predictor of behavior [28, 29]. Affordance theory is well developed in the Management Information Systems literature [e.g., 30, 31]. Central to this theory is that objects have properties, or features in the context of information technology, and users perceive the utility of these features (i.e. what they afford). Technologies like those enabling online sales, can: 1) support multiple affordances [32]; 2) can be both constraining and enabling [33]; 3) are perceived relationally [33, 34]; 4) can be misperceived or not recognized [35]; and 5) are individualised, collective, and shared [32]. Our finding that perceptions of affordances are impacted by personal identity motives suggests that affordances are not just relational, in the sense that affordances are different from one group of users to another and that different observers/users will perceive different affordances, they are also personal. They are personal, not just in the sense of individual differences, but in the sense that they relate to self by being aligned to personal identity motives.

Affordances are previously known to be goaldirected [34] but our findings suggest that one important source of these goals is overcoming threats to identity motives. This enhances affordance theory by illuminating a missing theoretical mechanism for affordance actualization [e.g., 36] and by addressing why individuals, such as entrepreneurs, adopt and use technology differently. They do so when technology affordances allow them to resolve threats to (or support) identity motives. Unearthing this relation between technology affordances and identity, a novel contribution of this work, promises to become a fruitful avenue for more in-depth studies of small business management in particular, but also MIS in general.

Second, by finding that small retail entrepreneurs' identity motives impacted their strategic technology adoption decisions when faced with knowledge uncertainty during the COVID19 pandemic, our work begins to address calls for micro-foundational identity research [e.g, 37], and introduces the concept of identity motives, and threats to those motives. This more nuanced understanding of the mechanism for influence of personal identity may be helpful to other scholars seeking to understand other goal-directed behaviors such as networking, or the development and use of social capital, where processes and outcomes may also be linked to identity motives.

Furthermore, we extend identity process theory [e.g., 22] by recognizing that internally-focused identity motives may manifest differently than externallyfocused identity motives. This is useful because it suggests that rather than there being individual differences in entrepreneurs' strategic decision-making, there may be groups of entrepreneurs whose identity motives are internally-focused and other groups of entrepreneurs whose identity motives are externallyfocused. These groups of entrepreneurs may perceive knowledge differently, and differentially trust knowledge sources. Thus they may respond differently with knowledge informed strategy. While individual differences are idiosyncratic, making resilience and other strategy prescription difficult, the potential of identity motive groupings means that strategic response training, including knowledge management, might be developed by grouping to increase resilience and other outcomes. These and other effects of identity motive groupings may be observed in contexts well beyond MDC events.

Third, this mechanism finding also informs adaptive theory. Adaptive theory has mainly been applied at the organization level of analysis, with a particular focus in entrepreneurship on organizational learning, knowledge, and capability development to enact strategic adaptation. Recently, Li [38] examines the possible link between organization identity and learning, finding that organizations with different identities learn differently in terms of specific common practices, knowledge, and expertise. Our finding that identity motives, at the individual level of analysis, impact adaptive strategy in an extreme change event, contributes to adaptive theory by illuminating identity motives as a key mechanism for adaptive organizational change.

Fourth, with respect to one of the dominant perspectives of adaptive theory's concept of resilience, our findings support the perspective that resilience is a mindset that helps some entrepreneurs face adversity and overcome challenge, not a trait or characteristic of entrepreneurs. Traits reflecting deep beliefs are mainly innate and are difficult to change [39]. A mindset conceptualization of resilience means that resilience can be learned, and likely trained, as discussed further below. Such training would also help make entrepreneurs' organizations more resilient because the strategic decisions of small business entrepreneurs are central to the survival and performance of their businesses.

Work is needed to further understand resilience as a mindset. Does resilience emerge as an outcome from an entrepreneurial mindset, or is it a mindset of its own? We think it is a mindset of its own, but what are the elements or dimensions of such a mindset? Previous literature suggests adaptability, transformability, perseverance, tenacity, and vulnerability are part of it [40-43] but are there other elements and how do they manifest individually and collectively? How is resilience mindset related to having a growth mindset $[44,45]$. A growth mindset reflects belief that intelligence can evolve or be developed purposefully, 
and it is thought to be related to the ability of people to better adapt to external forces than those having a fixed mindset [45]. Further, how is it related to a paradox mindset [e.g., 46] since entrepreneurs faced with extreme external change events need to resolve the paradox of having to adapt to change without limiting their ability to revert back to the original strategy should the event be short-lived or not as impactful as first feared. The notion that resilience is a mindset and a mindset distinct from, but related to, other mindsets is intriguing because this would suggest that resilience can be learned and strengthened.

\subsection{Contributions to practice and education}

Our findings suggest that threats to externallyfocused identity motives may encourage technology adoption as a means of resilience enactment by influencing entrepreneurs' perceptions of enabling and disabling technology affordances. This has a number of implications for practice and education, and we highlight three. First, some identity motives may better drive organizational resilience and that bright-side knowledge may trigger different identity motivations than dark-side knowledge. Entrepreneurs who learn to recognize their driving identity motives, and the possible impact of these motives on their decisionmaking, will be better armed to make consciouslydriven, not subconsciously-driven, strategic decisions. Training on recognizing identity motives is a first step in the process.

Second, entrepreneurs who understand, and are better able to assess, their related knowledge stock of enabling and disabling business technology affordances are likely to make well-informed adoption choices. This, too, requires training, not only so that entrepreneurs know the characteristics and capabilities of the technology, but also that they go beyond the technology functionality and understand that affordances result from the relationship between all of the actors (e.g., individuals, organizations) and artifacts. As a result, although the characteristics of a given technology might be common across small businesses, the actualizations of affordances are not. Teaching entrepreneurs about this important difference will likely lead to more mindful approaches to affordance actualization and adoption of technology. It also suggests that knowledge management could prime positive and negative affordance perceptions. Third, these findings suggest that, as part of their

\footnotetext{
${ }^{1}$ Digital Main Street: https://digitalmainstreet.ca/

${ }^{2}$ Launch Online Grant Program:

https://launchonline.ca/ accessed
}

ecosystem resilience strategy, regional and local governments and entrepreneurship support organizations should develop digitalization programs, similar to Digital Main Street $^{1}$, to help small business entrepreneurs learn business technologies to help them better understand and assess related affordances for their businesses. They should also provide funding, similar to the LaunchOnline ${ }^{2}$ grant program, to support small business entrepreneurs' efforts to develop online stores and implement other digital strategies. Our findings, however, suggest that online store adoption decisions by entrepreneurs are not simply financially driven. Funders need to recognize the influence of knowledge stocks and uncertainty on internally-driven and externally-driven identity motives and the concomitant assessment of technology affordances that help drive their choices if such programs are to be successful. Program administrators can proactively create educational materials and face-to-face or online seminars/videos that help counteract (or support) the influence of identity motives, and encourage assessments that view the affordances of new online store technology as enabling. Digital assistance and funding programs are more likely to get uptake from entrepreneurs with externally aligned identity motives. Customer acquisition strategies for these programs should also proactively reach out to business owners with internally aligned identity motives.

Conceptualizing resilience, at the individual level of analysis, as a mindset, suggests that resilience, such as avoiding the dark-side of knowledge, can be learned, and much like having an entrepreneurial mindset or a growth mindset, it should be possible to develop training programs to develop a resilience mindset. Further research is needed to understand the range of thinking that embodies a resilience mindset and sets it apart from related mindset and cognition constructs. However, our first-order coding suggests this mindset involves optimism, adaptability, being ready for change, taking action, and persevering until things are done. Developing such action-oriented cognitions requires deliberate practice $[39,47]$ and to practice resilience, entrepreneurs and prospective entrepreneurs need to build experience with, confidence in, and tools for, dealing with adversity. Because coaching and mentorship helps entrepreneurs make sense of experiences [47] it would be important for resilience mindset-focused experiential learning initiatives to include opportunities for knowledge reflection and internalization. Such initiatives would assist in creating greater individual resilience and greater entrepreneurial 
ecosystem resilience to help entrepreneurs overcome future adversity.

\subsection{Limitations and conclusions}

Our qualitative, retroduction research identified insights that help extend theory and provide direction for practice and education, but our findings need verification using confirmatory methods. While insights were gained about resilience enactment during an extreme MDC event, it is not clear if, to what extent, or how, our findings apply to other, possibly more common, unexpected external change events. Studying extreme events is useful, however, to test boundary conditions, and the COVID19 pandemic provided the opportunity to test boundary conditions for resilience enactment by severely effecting almost all small business entrepreneurs, all at the same time, removing the obfuscating effects of context, and allowing examination of decision-making processes. We found, in the COVID19 crisis knowledge uncertainty context, that identity motives, perceptions of technology affordances, and resilience mindsets of retail small business entrepreneurs intertwine to impact their resilience enacting technology adoption decisions. These findings are generalizable to theory [48] and provide direction for future research that is generalizable to broader populations of entrepreneurs. Such research is needed to understand the role of identity motives, technology affordances, and resilience mindset on resilience enactment in contexts beyond retail small business facing massive discontinuous change. Beyond resilience, investigation of the effects of identity motives could also be fruitful in other domains of research, such as under-standing differences in opportunity recognition, the accrual and use of social capital, and networking behavior. Our work illuminate how entrepreneurs minimize, prevent or respond to the dark side of knowledge. It is our hope that the work presented here will motivate other researchers to pursue studies of small business resilience in the face of the dark side of knowledge, and to investigate the effects of identity motives and technology affordances. This is to ensure that we are all not only better prepared for future events of massive discontinuous change, but also that we will be better prepared to address knowledge uncertainty and knowledge stocks and flows that are questionable in nature.

\section{References}

1. Ayala, J.-C. and G. Manzano, The resilience of the entrepreneur. Influence on the success of the business. A longitudinal analysis. Journal of Economic Psychology, 2014. 42: p. 126-135.
2. Corner, P.D., S. Singh, and K. Pavlovich, Entrepreneurial resilience and venture failure. International Small Business Journal, 2017. 35(6): p. 687-708.

3. Winn, M., et al., Impacts from climate change on organizations: a conceptual foundation. Business strategy and the environment, 2011. 20(3): p. 157-173.

4. Dewald, J. and F. Bowen, Storm clouds and silver linings: Responding to disruptive innovations through cognitive resilience. Entrepreneurship Theory and Practice, 2010. 34(1): p. 197-218.

5. Shepherd, D.A., F.P. Saade, and J. Wincent, How to circumvent adversity? Refugee-entrepreneurs' resilience in the face of substantial and persistent adversity. Journal of Business Venturing, 2020. 35(4): p. 105940.

6. Shepherd, D.A. and T.A. Williams, Local venturing as compassion organizing in the aftermath of a natural disaster: The role of localness and community in reducing suffering. Journal of Management Studies, 2014. 51(6): p. 952-994.

7. Cowling, M., et al., What really happens to small and medium-sized enterprises in a global economic recession? UK evidence on sales and job dynamics. International Small Business Journal, 2015. 33(5): p. 488-513.

8. Davidsson, P. and S.R. Gordon, Much ado about nothing? The surprising persistence of nascent entrepreneurs through macroeconomic crisis. Entrepreneurship Theory and Practice, 2016. 40(4): p. 915-941.

9. Fong, R., et al., Pathways to self-sufficiency: Successful entrepreneurship for refugees. Journal of Ethnic \& Cultural Diversity in Social Work, 2007. 16(1-2): p. 127-159.

10. Powell, E.E. and T. Baker, It's what you make of it: Founder identity and enacting strategic responses to adversity. Academy of Management Journal, 2014. 57(5): p. 1406-1433.

11. Anderson, A., J. Park, and S. Jack, Entrepreneurial social capital: Conceptualizing social capital in new high-tech firms. International small business journal, 2007. 25(3): p. 245-272.

12. Dodd, S., A. Anderson, and S. Jack, "Let them not make me a stone"-repositioning entrepreneurship. Journal of Small Business Management, 2021: p. 1-29.

13. Harre, R. and E. Madden, Basil Blackwell. 1975, Oxford.

14. Sobh, R. and C. Perry, Research design and data analysis in realism research. European Journal of marketing, 2006. 40(11/12): p. 1194-1209.

15. Lassalle, P. and E. Shaw, Trailing wives and constrained agency among women migrant entrepreneurs: an intersectional perspective. Entrepreneurship Theory and Practice, 2021: p. 1042258721990331.

16. Danermark, B., M. Ekström, and J.C. Karlsson, Explaining society: Critical realism in the social sciences. 2019: Routledge. 
17. Rao Hill, S. and C. Perry, Convergent interviewing: a starting methodology for an enterprise research program. 2007, Edward Elgar Publishing Limited.

18. Kvale, S., Interviews: An introduction to qualitative research interviewing. 1994: Sage Publications, Inc.

19. Balogun, J., A. Sigismund Huff, and P. Johnson, Three responses to the methodological challenges of studying strategizing. Phyl, Three Responses to the Methodological Challenges of Studying Strategizing, 2003.

20. Priyono, A., A. Moin, and V.N.A.O. Putri, Identifying Digital Transformation Paths in the Business Model of SMEs during the COVID-19 Pandemic. Journal of Open Innovation: Technology, Market, and Complexity, 2020. 6(4): p. 104.

21. Suddaby, R., From the editors: What grounded theory is not. 2006, Academy of Management Briarcliff Manor, NY 10510.

22. Vignoles, V.L., Identity motives, in Handbook of identity theory and research. 2011, Springer. p. 403432.

23. Carver, C.S. and M.F. Scheier, Control theory: $A$ useful conceptual framework for personality-social, clinical, and health psychology. Psychological bulletin, 1982. 92(1): p. 111

24. Kyratsis, Y., et al., Health systems in transition: Professional identity work in the context of shifting institutional logics. Academy of Management Journal, 2017. 60(2): p. 610-641.

25. Gregg, A.P., C. Sedikides, and J.E. Gebauer, Dynamics of identity: Between self-enhancement and selfassessment, in Handbook of identity theory and research. 2011, Springer. p. 305-327.

26. Oyserman, D. and L. James, Possible selves: From content to process. 2009.

27. Herbane, B., Rethinking organizational resilience and strategic renewal in SMEs. Entrepreneurship and regional development, 2019. 31(5-6): p. 476-495.

28. Nambisan, S., M. Wright, and M. Feldman, The digital transformation of innovation and entrepreneurship: Progress, challenges and key themes. Research Policy, 2019. 48(8): p. 103773.

29. Smith, C., J.B. Smith, and E. Shaw, Embracing digital networks: Entrepreneurs' social capital online. Journal of Business Venturing, 2017. 32(1): p. 18-34.

30. Gibson, J.J., The theory of affordances. Hilldale, USA, 1977. 1(2).

31. Volkoff, O. and D.M. Strong, Affordance theory and how to use it in IS research. The Routledge Companion to Management Information System. New York: Routledge, 2018.

32. Leonardi, P.M., When does technology use enable network change in organizations? A comparative study of feature use and shared affordances. MIS quarterly, 2013: p. 749-775.
33. Hutchby, I., Technologies, texts and affordances. Sociology, 2001. 35(2): p. 441-456.

34. Volkoff, O. and D.M. Strong, Critical realism and affordances: Theorizing IT-associated organizational change processes. MIS quarterly, 2013: p. 819-834.

35. Gaver, W.W. Technology affordances. in Proceedings of the SIGCHI conference on Human factors in computing systems. 1991.

36. Strong, D.M., et al., A theory of organization-EHR affordance actualization. Journal of the Association for Information Systems, 2014. 15(2): p. 2.

37. Mmbaga, N.A., et al., A review of and future agenda for research on identity in entrepreneurship. Journal of Business Venturing, 2020. 35(6): p. 106049.

38. Li, C.-H., AN EXPLORATORY STUDY OF ORGANIZATIONAL LEARNING NETWORKS: AN IDENTITY APPROACH. International Journal of Organizational Innovation, 2017. 10(1): p. 1.

39. Krueger, N.F., What Lies Beneath? The Experiential Essence of Entrepreneurial Thinking. Entrepreneurship theory and practice, 2007. 31(1): p. 123-138.

40. King, D.D., The untapped potential in employee resilience: Specific recommendations for research and practice. Industrial and Organizational Psychology, 2016. 9(2): p. 405.

41. Bullough, A., M. Renko, and T. Myatt, Danger zone entrepreneurs: the importance of resilience and selfefficacy for entrepreneurial intentions.

Entrepreneurship Theory and Practice, 2014. 38(3): p. 473-499.

42. Linnenluecke, M.K., Resilience in business and management research: A review of influential publications and a research agenda. International Journal of Management Reviews, 2017. 19(1): p. 4-30.

43. Nisula, A.-M. and H. Olander, The role of motivations and self-concepts in university graduate entrepreneurs' creativity and resilience. Journal of Small Business Management, 2020: p. 1-30.

44. Burnette, J.L., et al., A growth mindset intervention: Enhancing students' entrepreneurial self-efficacy and career development. Entrepreneurship Theory and Practice, 2020. 44(5): p. 878-908.

45. Dweck, C.S., Mindset: The new psychology of success. 2008: Random House Digital, Inc.

46. Sleesman, D.J., Pushing through the tension while stuck in the mud: Paradox mindset and escalation of commitment. Organizational Behavior and Human Decision Processes, 2019. 155: p. 83-96.

47. Dew, N., et al., Toward deliberate practice in the development of entrepreneurial expertise: The anatomy of the effectual ask. The Cambridge handbook of expertise and expert performance, 2018: p. 389-412.

48. Perry, C., Processes of a case study methodology for postgraduate research in marketing. European Journal of Marketing, 1998. 


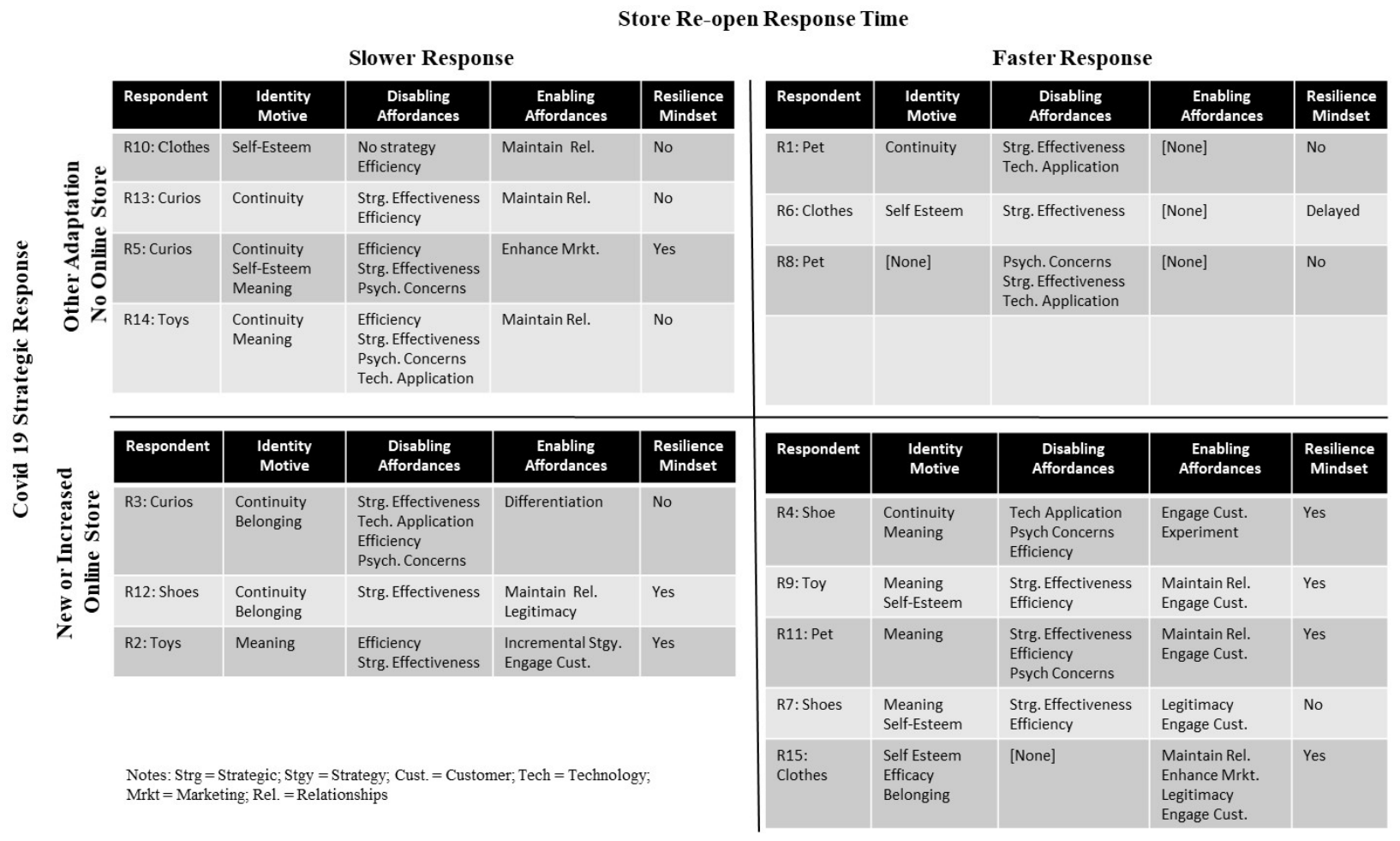

Table 1 Retail Entrepreneurs' Strategic Response to the First Wave of COVID19 